\title{
Colonias militares y civiles del siglo xIX: Una aproximación a las utopías urbanas del norte de Coahuila
}

\author{
Alejandro González Milea*
}

\section{Resumen}

El artículo argumenta que en el norte de Coahuila, a lo largo del siglo XIX, algunos nuevos centros de población estuvieron influenciados -en sus trazados y organización espacial- por los reglamentos para establecer colonias militares. Mediante una revisión del carácter doctrinario de sus medidas y disposiciones, y con el estudio del caso de El Remolino -entre otras colonias para civiles y repatriados, referidas con mero fin ilustrativo-, es posible corroborar una conocida idea según la cual las utopías mexicanas abrevaron de una tradición formada por breves resúmenes de ideales colectivos y no fueron ejercicios creativos de imaginación o fábulas ociosas. El empleo recurrente del damero, a decir del trazado de calles y manzanas en cuadros, permite avanzar en la definición de rasgos de un tipo de ciudad ideal que es necesario incorporar - por su larga persistencia en el tiempo- a la historia del urbanismo y de la planificación en el noreste de México, pues asoció una conciencia sobre las necesidades de la población con una concepción de la unidad artística.

Palabras clave: colonias militares, colonias civiles, utopías urbanas.

\begin{abstract}
The article sustains that, in North Coahuila, during XIX century, the new population centers were influenced by military colonies reglamentos. A revision of its measures and dispositions, also with the case study of El Remolino -and other civil and repatriated colonies-, it is possible to corroborate a familiar idea which states that the Mexican utopias were inspired from a tradition formed of short resumes of collective ideals, but were not creative exercises of imagination or idle fables. The recurrent using of damero -a square trace of streets and blocks- permits to advance in the definition of an ideal city type that its necessary to incorporate to the urbanism and planning history of Nord-eastern Mexico, because it associates a conscience of the population needs with an artistic unity conception.
\end{abstract}

Keywords: military colonies, civil colonies, urban utopias.

* Investigador de la Universidad Autónoma de Ciudad Juárez. Correo electrónico: alejandromilea@prodigy.net.mx. 


\section{Introducción}

A todo lo largo del siglo xIx, una constante del proyecto político del estado de Coahuila fue sin duda el establecimiento de nuevas poblaciones. Desde la década de 1820 hasta los albores de la revolución de 1910, la colonización se impulsó de modo constante y similar a como se hizo en otros estados del norte (Sonora y Chihuahua, por ejemplo). En México no fue extraño que el empleo del término colonización y sus diversos significados variaran, pues en primera instancia, el estire y afloje en el uso de la palabra revelaba los debates que tomaban lugar tanto en los confines territoriales como en las ciudades ya consolidadas con gobierno bien instalado. Mientras algunos funcionarios y diputados creían que lo conveniente era abrir el país a la inmigración extranjera, otros -en cambio- pensaban más adecuado alentar a mexicanos para que ocuparan tierras desiertas, feraces y plenas de recursos naturales del poco conocido y supuestamente vacío norte. De este modo, también se entreveraban discusiones en torno a la necesidad de construir un antemural de la nacionalidad para enfrentar la expansión de ambiciones extranjeras, alcanzar la pacificación del indio nómada y organizar una industria propia. Asimismo, persistió la dificultad de resolver si había que alentar compañías de colonización privadas o, por el contrario, reducir cualquier acción a la esfera de gobierno ( $c f$. Berninger, 1974; González, 1960). ${ }^{1}$

Como podrá adivinarse, una parte del problema era la discusión de las bases sobre las cuales debía construirse la nueva nación: adoptar modelos europeos y extranjeros, o continuar con las experiencias de "poblamiento" de casi 300 años. Los anteriores puntos a debate -entre liberales y conservadores- pudieron observarse con mucha nitidez en estas latitudes, pues junto con la ocupación del territorio afloraron a lo largo del siglo diversas soluciones urbanas. En nuestros días, sus planos ideales desde luego deberían mantener un diálogo fructífero con las ya conocidas ensoñaciones que abarcan a las comunidades cooperativas de Owen y a los falansterios de Fourier y Considérant entre otras. Pero, de este modo, quizá habría demasiado énfasis en los rasgos anticipadores de modernidad contenidos en el modelo de Ciudad Jardín de Ebenezer Howard, y la inscripción de los planes ideales del norte

1 Estos son algunos temas considerados como más representativos del debate en torno a la "colonización" en el siglo xix en México. 
mexicano en la historiografía sobre la planificación y el urbanismo requiere otra perspectiva o abordaje. Muy poco sabemos, por ejemplo, del efecto que provocó la observación e inspiración del modelo de Sinapia, atribuido a Pedro Rodríguez -conde de Campomanes- en España ( $c f$. Aviles, 1976; Oliveras, 1998)..$^{2} \mathrm{Y}$ antes que recurrir a un manejo del concepto de utopía que gira en torno a ideales del socialismo en su evolución decimonónica -y como lo han expuesto J. L. Abramson y Carlos Illades-, aquí interesa seguir la línea trazada por investigadores como Helen Rosenau (1999) y Virgilio Vercelloni (1996), cuyo concepto de ciudad ideal representa la cristalización de ideas más viejas, persistentes por inalcanzables. Así, considerando la persistencia de ciertas instituciones borbónicas en América -como fue el caso de las compañías presidiales-, en este texto me interesa referirme al carácter idealista de los proyectos para "colonias militares" y a su relación en el tiempo con la emergencia de las denominadas "colonias civiles".

De forma semejante a como sucedió en el siglo XvIII, en que los presidios ya consolidados daban lugar a salidas de civiles para fundar nuevas poblaciones, las colonias militares del siglo XIX revelaron este mismo propósito -u horizonte- que en esencia fue el de avanzar una frontera de "civilización". El problema fue el contexto cambiante en que este avance fue tomando lugar, por ejemplo, por la definición de la línea internacional de 1848, de la cual derivó un propósito adicional y aparentemente inconexo: la fundación de nuevas poblaciones con repatriados mexicanos y -por lo mismo- el acrecentamiento de prácticas de colonización interna con civiles ( $c f$. González, 2000)..$^{3}$

Resolver su grado de concreción impone atender a lo que estaba ocurriendo en cada estado del norte, sobre todo en sus proyectos políticos y evolución de jurisdicciones territoriales. ${ }^{4}$

\footnotetext{
2 Me refiero a los principales rasgos de este modelo tal y como fueron expuestos por Miguel Aviles (1976), quien sugiere características y problemas comunes entre España y algunas posesiones españolas en América.

3 El tipo de colonización que impulsó el tratado de paz entre los Estados Unidos de América y México constituye un tema poco abordado por los estudiosos y prácticamente ausente para la historia de la planificación ideal y del urbanismo en el norte.

4 Desde 1848 se decretaron disposiciones que afectarían esta modalidad de colonización, como la orden de que fueran los gobernadores de los estados del norte los encargados de reglamentar la organización de colonias civiles, contenida en un decreto
} 
Por lo anterior, en una primera sección de este texto me ocupo de generalidades de los planes para fortificar la frontera y de algunas características de los proyectos urbanos que se pensó poner en práctica. La intención es discutir el carácter normativo de una forma específica de ciudad ideal considerando los dos planes detallados que se elaboraron y publicaron en 1848 y en 1869. En un siguiente apartado ejemplifico los factores y circunstancias de la colonización impulsada bajo este modelo en Coahuila, revelando hechos que sugieren una conciencia del interés por continuar inspirándose en la tradición en vez de elaborar imágenes creativas sobre el futuro. Asimismo, explico un caso concreto de colonia civil (El Remolino) y repaso sus condiciones de fundación, medición y primeras obras realizadas, con la intención de mostrar sus relaciones con planes militares. Por último, ofrezco varios resultados de exploraciones físicas de éste y otros barruntos de ciudad semejantes que permiten prefigurar el destino hacia el cual apuntaban tales utopías urbanas.

Dado que el texto ofrece una aproximación a un tema poco estudiado, varias conclusiones deben valorarse como tentativas. La colonización del norte mexicano exige un considerable número de estudios de caso; sus conclusiones invitarían a hacer reformulaciones de una temporalidad más larga para -en última instancia- inscribirlas dentro de la historiografía del Estado nacional. Pero, en especial, dichas conclusiones permitirían ubicar nuevos problemas de investigación en torno a la historia del urbanismo y la historia urbana.

\section{La ciudad ideal en los confines: colonias militares}

Para comprender la ocupación militar en el noreste, sobre todo a través de sus planes y proyectos urbanos en el siglo XIx, podrían revisarse las experiencias del general Manuel Mier y Terán en Texas entre finales de la década de 1820 y el año de 1836. De esta manera sería posible distinguir algunas medidas de continuidad de la política borbónica en la frontera, como por ejemplo, la fundación de colonias en donde se congregaría a indios de paz, la

mandado a publicar por el presidente, el general José Joaquín de Herrera. Véase Decreto publicado el 19 de agosto de 1848, Archivo Histórico del Congreso del Estado de Nuevo León (AHCENL), C54, E76, Ix Legislatura. 
organización de una industria emanada de sus circunstancias específicas y, de manera especial, el despliegue de un discurso consciente de civilización.

El conocido diario de la primera expedición de Mier y Terán -llevada a cabo en el noreste, desde 1827 en adelante- ilustra bien la amplia visión que tenía la exploración (de carácter militar y científico), pero sobre todo, el desconocimiento del noreste y la sorpresa frente al grado de consolidación que se había logrado mediante el sistema de presidios ( $c f$. Diario de viaje, 1850). Por otra parte, recientemente ha sido Alfredo Jiménez quien ha recordado a los historiadores una cuestión importante: que los militares enviados a las fronteras -en especial durante la última parte del reinado español- era gente con mucha experiencia ( $c f$. Jiménez, 2006).$^{5}$

Pero el espacio destinado a esta exposición no permite ahondar en estos antecedentes y parece plausible comenzar en el momento en que la experiencia texana terminó por infundir de nueva certeza a la urgencia de resguardar la frontera nacional. ${ }^{6}$ Las características de los proyectos para colonias militares, publicados en 1848 y 1869, alertan sobre la necesidad de estudiarlos a detalle, pues abundan las visiones encontradas entre estudiosos que rozan el tema de la efectividad de la ocupación del territorio septentrional según el modelo español.

Desde 1840, Juan Nepomuceno Almonte -ministro de guerra y marinaya prometía el establecimiento de colonias militares con familias mexicanas y en terrenos baldíos. El objetivo sería que dichas colonias se ocuparan con personas versadas en giros mercantiles, en la labranza y en las artes, pero el plan concreto todavía estaba por realizarse (Memoria, 1840:49). Desde la misma oficina, los siguientes años se ventilaron muchas cuestiones relativas a las incursiones de indios en los "Departamentos internos de oriente y occidente". Si bien se trabajaba sobre varias medidas, como la construcción de fortines y definición de las funciones de las compañías presidiales -restablecidas en 1826-, interesa en especial conocer cómo se

5 Compárese con la distinta visión que David J. Weber ofrece sobre este tema cuando se refiere de modo constante al abandono de las posesiones españolas.

6 En 2009, la doctora Rina Ortíz Lazo leyó una conmovedora ponencia en Brownsville, Texas (4th International Colloquium of Northeast Mexico and Texas) que revela la tristeza con que Manuel de Mier y Terán - pocos años antes de su muerte- veía el avance de angloamericanos en Texas -entre 1830 y 1832-, frente a la difícil ocupación mexicana que paralelamente había intentado impulsar. 
reflexionaba sobre la experiencia de décadas anteriores con los presidios. La Memoria del año 1845, por ejemplo, llamaba la atención sobre los puntos positivos que se habían alcanzado en las fronteras con los presidios: la represión del indio salvaje, la presencia constante de ingenieros hábiles en la ciencia militar, y en general "el florecimiento del país" por el surgimiento de pueblos o villas a partir de presidios "con municipalidad y su milicia nacional”. Sin embargo, también se lamentaban cosas, como la destrucción -sobre todo a partir de los acontecimientos de 1810- de lo que se decía había sido "un sistema hábilmente concebido y enérgicamente ejecutado". También se habían despertado odios entre autoridades y rivalidades con los soldados (Memoria, 1845:27-28). La Memoria de 1846 terminaba por recalcar la urgencia de presentar un plan ante el Congreso y se designó una junta -formada por José Joaquín Herrera, Anastasio Bustamante, Vicente Filisola, Pedro María Anaya e Isidro Reyes- para elaborarlo (Memoria, 1846:33-34).

Sólo fue hasta el decreto publicado en 1848 por el entonces presidente mexicano José Joaquín Herrera, que se presentó el plan detallado con su reglamento. La idea general contemplaba el establecimiento de colonias militares en tres fronteras del país: los distintos estados del norte, la Sierra Gorda (estados de México, Querétaro y San Luis Potosí) y Tehuantepec en el sur, para conservar la integridad territorial y defender a los estados de las incursiones de los bárbaros y el control de rebeliones. Si bien se publicaron reglamentos específicos para cada zona, en términos generales se contemplaban aspectos comunes y es muy probable que las del norte definieran el modelo a seguir -en una primera instancia- para todas las demás. Junto con las colonias militares, por ejemplo, también se construirían "plazas fuertes" y todo el plan contaría con un presupuesto fijo, cuidado por el gobierno, hasta que los colonos estuvieran en condiciones de formar un nuevo pueblo, objetivo último de toda la idea. La cooperación de los gobernadores sería esencial en la definición de sitios para ambos propósitos, pues en primer término sólo se indicaron posiciones tentativas, pero su participación también sería vital para comunicar a la ciudad de México que se había formado ya una población civil. Este último punto es de especial interés pues el decreto señalaba que este acto -suponemos la posibilidad de problemas de esferas de autonomía- de ninguna manera podría darse sin antes asegurar la defensa (Colonias Militares, 1848). 
El plan era ambicioso pues, en primera instancia, se definieron 18 puntos para después ubicar cuál sería el sitio exacto de cada establecimiento. Para obtener los terrenos necesarios se indemnizaría a los propietarios particulares, en caso de ser necesario, para que cada colonia contara con una superficie de ocho sitios de ganado mayor. ${ }^{7}$ Desde luego, las colonias estarían gobernadas por militares de distintos rangos, tanto en lo tocante a su régimen interior como en el territorial, pues se contemplaban subinspectores, inspectores e inspectores generales. Al tiempo que se pensaba que los soldados se dedicarían también a la agricultura -además de labores de fortificación, defensa e incluso fabricación de armas-, también se contempló que a la convocatoria asistieran civiles. Por esto mismo se establecieron regímenes diferentes de justicia: jueces militares y de paz (Colonias Militares, 1848).

El gobierno general suministraría el dinero e implementos que se requirieran para establecer la defensa y la colonia propiamente dichas. Dichos gastos irían encaminados a pagar sueldos de la tropa, pero también del capellán, cirujano, preceptor de primeras letras, agrimensor, obreros y altos mandos. Asimismo, para lo que se denominó "agasajo de los indios", es decir, sumas y bienes (regalos) mediante los cuales se mantenía a los indios de paz conformes o satisfechos. No queda claro el apoyo específico para los vecinos, aunque el reglamento repite el "interés común” bajo el cual deben realizarse todas las actividades para consolidar la población, desde la construcción de canales y casas, hasta las labores de campo. Lo evidente es que los civiles podrían alistarse en las armas en cualquier momento, y con esto obtendrían premios como porciones de tierra adicionales para la práctica agrícola (Colonias Militares, 1848).

El plano que sirve de guía a todos estos detalles revela varias cuestiones interesantes, como la plaza rectangular -así dispuesta para las "fiestas de a caballo"-, la perspectiva acusada hacia el sitio de la iglesia, los lotes rectangulares en lugar de cuadrados -que anuncian rasgos del urbanismo del siglo XIX-, entre otros. Pero sobre todo la expresión geométrica de un orden estable que, frente a la posibilidad explícita de someter variaciones de

7 Las correspondientes a la Sierra Gorda y a Tehuantepec sólo dispondrían, cada una, con la superficie de cuatro sitios de ganado mayor. Considérese la siguiente equivalencia: un sitio de ganado mayor = 1755.61 hectáreas; otras veces la equivalencia se refiere a un cuadro de cinco mil varas castellanas por lado. 
acuerdo con las circunstancias o a las características del sitio -incluso por la dificultad de concretar tan ambicioso plan en lo inmediato-, pudo en realidad dar resultados muy variados. Un plan para fortificar Santa Rosalía (hoy Ciudad Camargo, Chihuahua), por ejemplo, parecía resolver este problema de modo práctico y concreto. En 1846, se había contemplado construir muralla o palizada alrededor de toda el área poblada con una línea de cuatro mil veintinueve varas por lado (3384 metros por lado, aproximadamente), pero se resolvió que el solo propósito requeriría mucho tiempo y dinero, de modo que no se puso en práctica (Ponce, 1910:369-372).

Figura 1. Plan del edificio de una colonia

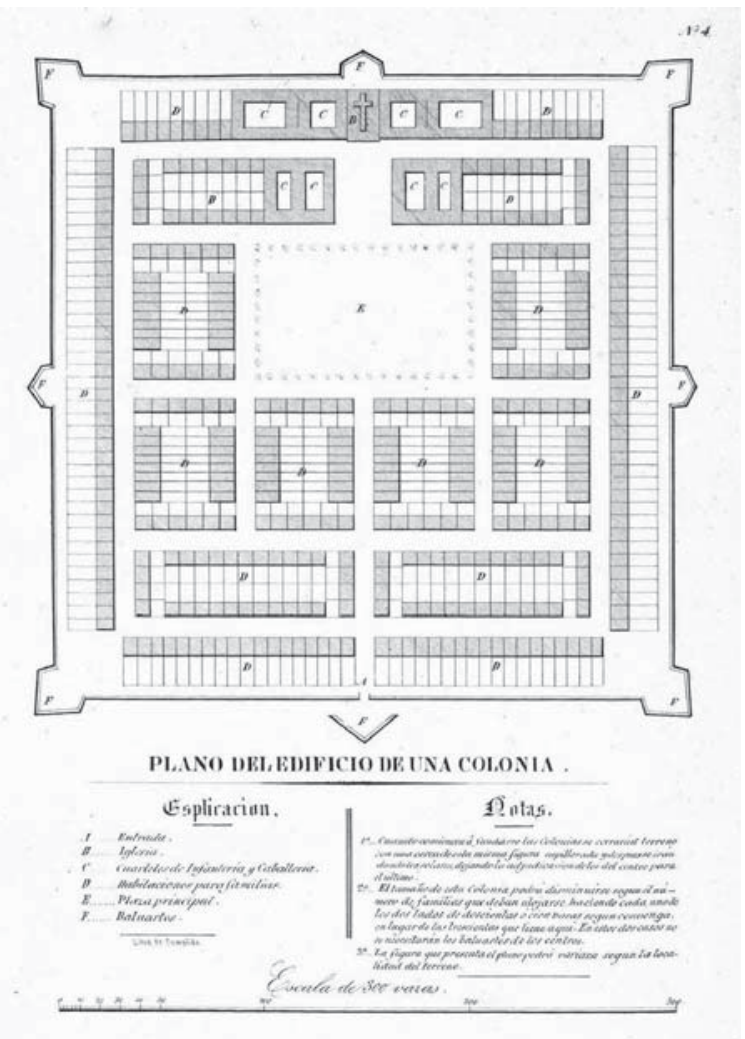

Tomado de: Colonias Militares, Plan para su establecimiento en las fronteras de oriente y occidente de la República (1848), Cuadro núm.4. 
En adelante, en la ciudad de México, los funcionarios del ramo de guerra y marina seguirían atentamente los avances del plan. En los informes de 1849, por ejemplo, se reconocía sin cortapisas que dicho proyecto debía considerarse como una reforma de los establecimientos que se habían denominado antes "compañías presidiales". Asimismo, se hacía patente la dificultad de establecer todas las colonias al mismo tiempo, pues el gasto era considerable y la tónica que prevalecía en la Memoria -publicada ese mismo año- era una especie de dificultad por reconocer la imposibilidad de llevar a cabo tan ambicioso propósito (Memoria, 1849:12-15). El deseo se manifestaba considerando que las colonias militares algún día podrían llegar a ser "la fuente de poblaciones civiles bien ordenadas que sirvan de base a ciudades populosas, para que disminuyan con su poder los inconvenientes de esa parte tan despoblada" (Memoria, 1849:16). El gasto que entonces se requiere para mantener en forma a los soldados es grande, y al mismo tiempo parece haber una preocupación por el compromiso con los civiles que se están involucrando. También se deslizaba un agudo sentido de crítica en estos informes que se enviaban a las oficinas centrales en la ciudad de México: "Los inconvenientes que se presentan para llevar a cabo con perfección una empresa, que se ha basado principalmente sobre el establecimiento del local de las colonias, en el que siembren, en el que sitúen a sus familias los colonos \& c., son bastantes para hacerla parecer ridícula, como lo es cualquiera combinación, cuando se falta a una de sus principales bases" (Memoria, 1849:17). El resultado cierto, aunque cruel, era que las familias de los colonos se encontraban "vagando" sin un lugar determinado de asiento.

Cada proyecto de colonia tendría sus problemas para consolidarse como tal en un sitio específico (Colonias Militares, 1848).8 Las memorias, publicadas entre 1850 y 1852 reseñarían hechos y conflictos que iban presentándose conforme avanzaban los trabajos, con un tono de crónica marcado, el análisis de posibilidades alternas y una constante actitud crítica. Las colonias, sobre todo en su parte militar -a decir de la frontera de oriente-se encontraban en movimiento, como la de San Vicente que anduvo en campaña

8 En lo tocante a la frontera de oriente, las colonias militares contempladas fueron siete (Coahuila), que considerando una orientación de poniente a oriente, estuvieron dispuestas en el orden siguiente: San Vicente, Monclova Viejo, Río Grande, El Pan, Monterrey y Guerrero. Cuando algunas de éstas lograron instalarse, su ubicación definitiva cambió. 
en Parras y en Santa Rosa, pero muy lejos de su lugar especificado de asiento. Otras, como la de Río Grande, la de Guerrero y la de Monclova Viejo, ya se habían instalado y habían comenzado algunas obras de construcción muy modestas. Mientras la primera se asentó en una antigua misión de franciscanos y la tercera tomó lugar en un sitio nuevo, la segunda quedó alejada de lo que se había previsto en el proyecto y reglamento iniciales. Se refieren obras de construcción diversas, como casas de madera con techos de zacate, construcción de acequias y fortificaciones. Pero las demás se encontraban haciendo expediciones de acuerdo con las necesidades de la guerra contra indios bárbaros (Memoria, 1851:20-25; Memoria, 1852:36-40).

\section{Figura 2}

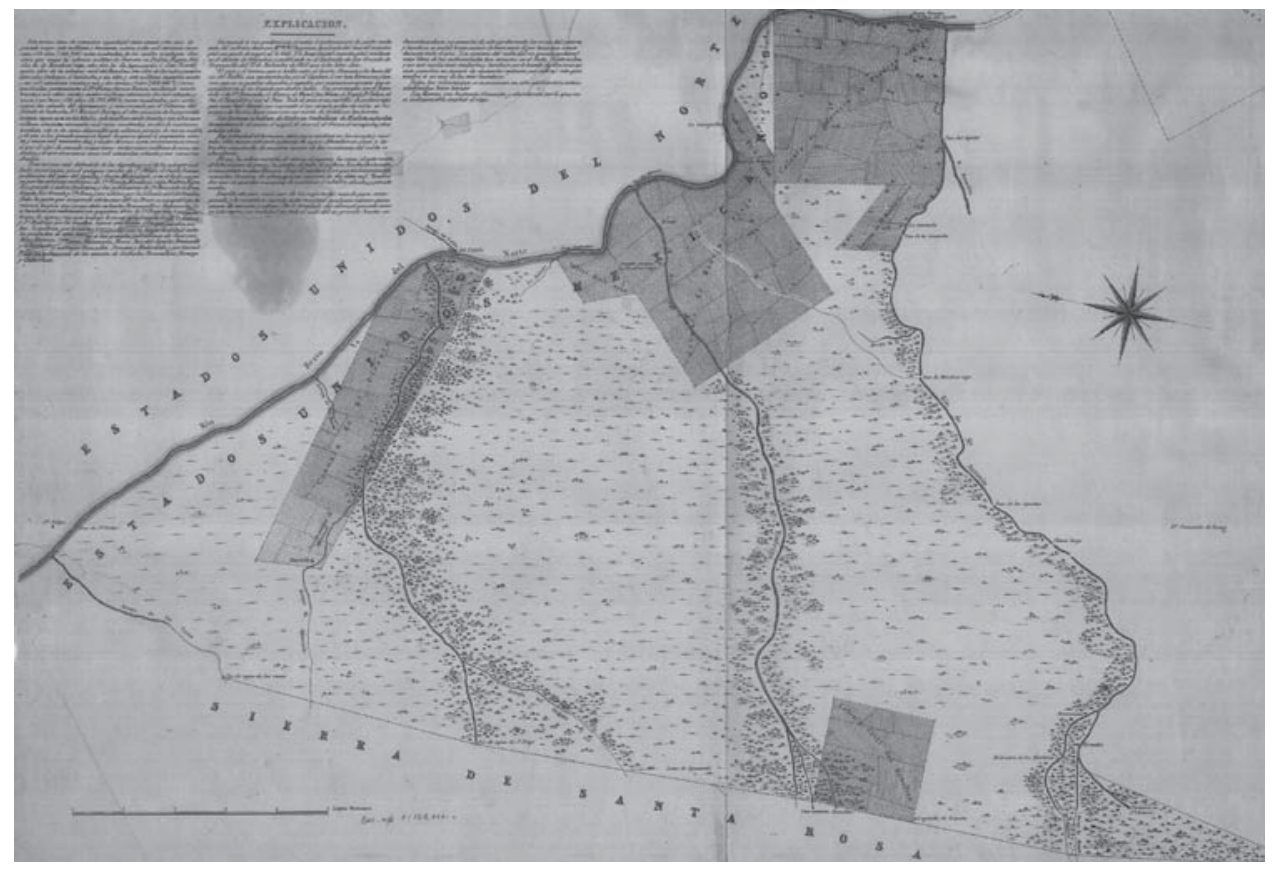

Terrenos destinados a las colonias militares de San Vicente, Monclova Viejo, Guerrero y Río Grande, en orden de izquierda a derecha. Adviértanse las zonas destinadas a indios, aledañas a ellas, y el sitio destinado a la colonia civil de El Remolino en la parte de abajo. Tomado de: Plano del terreno comprendido entre el Río de San Antonio y el Arroyo de las Vacas en el estado de Coahuila de la República Mexicana, copiado del original que obra en los Títulos de la propiedad, 1850, Mapoteca Manuel Orozco y Berra, Colección Orozco y Berra, núm. 1893. 
Un plano elaborado en 1850 (figura 2) sobre la ribera mexicana del Río Bravo -en Coahuila- deja una clara idea del modo en que se estaban definiendo los terrenos en donde habrían de instalarse las colonias militares en los entornos de la actual ciudad de Piedras Negras (donde se asentó, de modo definitivo, la colonia militar de Guerrero). Llaman la atención dos cosas: en primer lugar, las áreas dispuestas para que se asienten indios quickapoos (aledañas al fundo definido para las colonias), y en segundo, la designación de un sitio específico en la parte baja del mapa para una colonia civil que se formaría con repatriados. Volveré más adelante sobre este segundo punto, cuando me refiera al caso específico de la colonia El Remolino.

En lo que toca al segundo plan para colonias militares, debe tenerse en cuenta que en 1867 finalizó el Segundo Imperio. Durante este régimen fue común que se continuara hablando de la posibilidad de que las colonias militares se establecieran, y se agregó la idea de que en realidad constituían "colonias agrícolas militares" (Junta de Colonización, 1865). ${ }^{9}$ Una vez que Benito Juárez vuelve al poder, sin embargo, se publica el nuevo decreto para establecimiento de colonias militares; en esencia se resumen todas las previsiones tomadas en el anterior proyecto, salvo que para esta vez se pensó en 30 colonias esparcidas a lo largo de la frontera (Diccionario, 1868:173-174).

El prolegómeno del volumen publicado para reglamentar su establecimiento hacía un resumen de las anteriores experiencias con la clara intención de continuar en la misma línea de propósitos. A saber, de lo que se trataba era: erigir colonias militares y darles una organización civil, en primer lugar para que se formaran nuevas poblaciones, y en segundo, para que por este medio se atrajera a los indios a la vida civilizada (Reglamento, 1869). Aunque en rasgos generales existe una continuidad y similitud con el plan de 1848, cabe señalar variantes que en general tendían al perfeccionamiento de toda la idea. Tales detalles eran la formación de una "sociedad agrícola” por cada colonia como institución con estatuto reconocido, el trabajo enfocado al interés común mientras no se formara una nueva población, la negociación de tratados de paz con indios bárbaros -y su invitación- para que se asentaran en inmediaciones, la presencia de ingenieros

9 Me refiero al término que se puso a los debates, y soluciones, de un grupo dirigido por Francisco Pimentel, y que nuevamente discutía cómo debía impulsarse la colonización en el norte. 
para todo tipo de obras en las que fungirían como directores, la elaboración de informes científicos sobre los alrededores para beneficio de la industria, la imperativa de construir con materiales que se encontraran en los sitios, y una serie de pequeñas e interesantes previsiones acerca del tránsito que suponía la transferencia del orden y uso de espacios públicos principales, del orden militar hacia la sociedad civil (Reglamento, 1869).

\section{Figura 3}

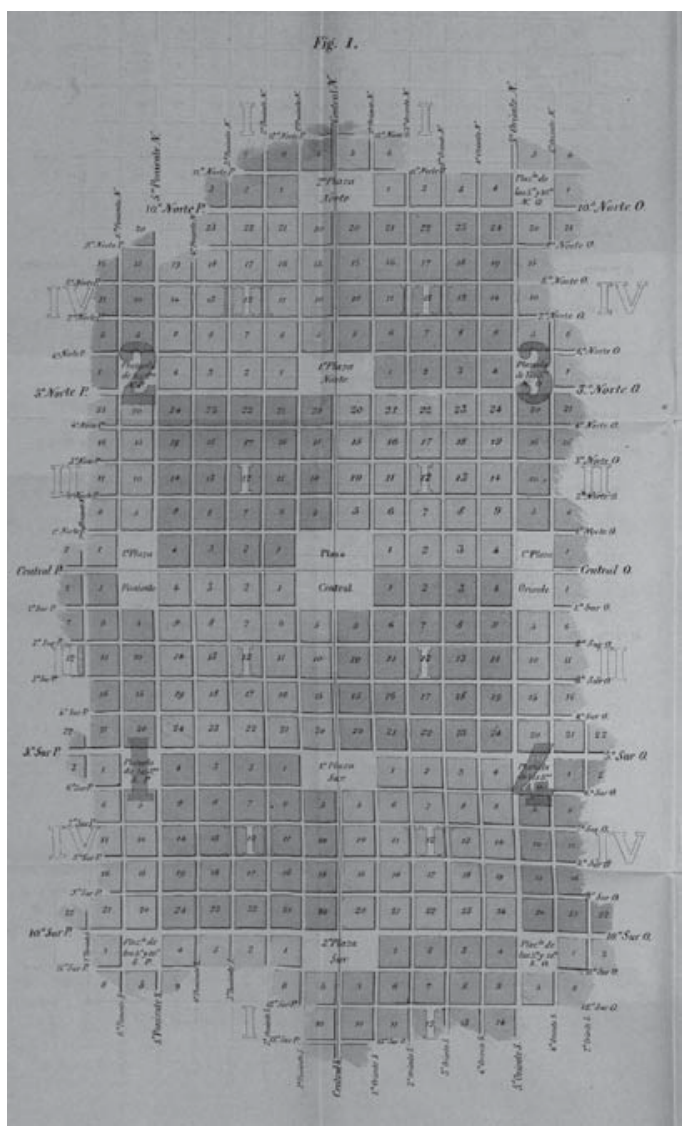

Trazado general de un modelo de colonia militar, que expresa la forma que obtendría una vez que se hubiera logrado consolidar la colonización civil. En un inicio, el fuerte estaría ubicado en la plaza central-definida por el cruce de dos calles centrales-, y luego sería demolido. Tomado de: Reglamento para el establecimiento de las colonias militares en la frontera norte, México, Imprenta del Gobierno en Palacio, a cargo de José M. Sandoval, 1869, Figura 1. 
Hablando otra vez del plano, que fue dibujado por el ingeniero Agustín Díaz -jefe de la comisión científica-, la idea es perfecta por su simetría. Revela también la intención de que primero se construiría un fuerte de no escasa dimensión, y de forma paulatina se irían repartiendo los lotes y tierras de los alrededores. Llaman la atención dos tipos de plaza consideradas como posibles, una al viejo modo que se indicaba dentro de las Recopilaciones de Leyes de Indias y otra más simple y flanqueada por calles. Parece oportuno señalar, respecto al trazo, que ya se habían debatido en el congreso de Nuevo León algunos pormenores del tipo de organización espacial que debía adoptarse para establecer colonias de repatriados. En 1850, con motivo de la fundación de la colonia Mier y Terán, se revisaron las "leyes recopiladas de Indias" para resolver el tipo de "arreglo" (trazo) que debía seguirse (Camacho, 1991:85-90). ${ }^{10}$ Dado que en Monterrey estaba asentada la inspección general de colonias militares de oriente, puede reconocerse un motivo de orientación doctrinal en la medida y en lo que toca al diseño urbano.

En el siguiente apartado abordo algunos pormenores que surgieron en el estado de Coahuila con motivo de la colonización de tipo civil. La finalidad es tratar de responder qué tanto la colonia civil se abrió paso más rápidamente de lo que podía prever el plan inicial elaborado por militares y llegó a tomar una suerte de vida propia; en especial, a partir de la definición de la línea internacional en 1848, y por ello, también con el arribo de repatriados y otras circunstancias locales que fueron de hecho paralelos al establecimiento de colonias militares. Esta intención parece pertinente una vez que se observa qué tan constante fue el movimiento de las compañías presidiales por el territorio a lo largo del siglo; y la construcción de sus grandes fuertes y áreas de población semeja más un deseo que una realidad. Para lo anterior, con particular énfasis me referiré al caso de la colonia civil El Remolino, cuyos promotores fueron militares.

10 Contrato aprobado de la cesión que se hace en Laredo de veintinueve leguas cuadradas de terreno para el establecimiento de una colonia civil, Monterrey, Año de 1850, AHCEnL, C38, E87, vII Legislatura; y Decreto No. 87. Se establece una colonia civil sobre la mesa situada enfrente al Paso de Villarreal en el Río Salado, confinando por el sur con los límites de la hacienda del Carrizal, Monterrey, 9 de Octubre de 1850, AHCENL, C41, E129, vIII Legislatura. 


\section{Coahuila: su colonización interna}

La elección del territorio coahuilense para investigar y exponer el problema de la ausencia de un plano de ciudad ideal en la historia del urbanismo en México -que anunciara una forma de modernidad específica, pero sobre todo propia- de ninguna manera es inocente. El territorio de la jurisdicción de Coahuila primero hubo de perder el fragmento correspondiente a Texas (1836), y más adelante quedó sujeto a los designios de Nuevo León durante un lapso en que los regímenes liberal e imperial también convivieron (1855-1867, de admitirse esta temporalidad significativa para el borde territorial). Quizá sólo una facción porfiriana pudo infundir efectos concretos en el ordenamiento de la política estatal (1884-1910), pero demasiado pronto emergió también una rama revolucionaria. Coahuila parece ser uno de los proyectos político-territoriales más puestos en duda durante una fase de construcción del Estado nacional del siglo xix, que como señaló una historiadora de la región, constituyó más un deseo anhelado que una realidad concreta sobre todo para la primera mitad de siglo (Gutiérrez, 2000:93-110). $Y$ sin embargo, Coahuila fue el estado que tuvo un incremento poblacional sin precedentes en el territorio mexicano entre 1850 y 1940, periodo en que su número de habitantes se incrementó ocho veces, mientras que la media para los estados limítrofes del norte fue de tres y media y la nacional de dos y media (De la Peña, 1950). De modo que tratar de responder a las preguntas de cómo ocurrió el poblamiento de Coahuila durante el siglo xix y qué modelos rigieron la ocupación -pero sobre todo, identificar y verificar cuáles fueron sus soluciones urbanas- invita a la exploración de patrones.

En 1851, el vicegobernador de Coahuila recalcaba en su Memoria las esperanzas que tenía en el plan del gobierno general para establecer colonias militares. Sin embargo, también indicaba que ello de ninguna forma significaría que no se estimulara la "emigración" para lograr que se fundaran nuevas poblaciones (Memoria, 1851:2-3). Dadas las referencias a la necesidad de proteger la frontera de invasores, es pertinente deducir que se refería a migraciones internas, antes que a las debidas a extranjeros únicamente. Ambos proyectos para colonias militares contemplaban aspectos como el alistamiento y la jubilación, de modo que no fue extraño que del sector militar surgieran ideas -o tendencias- para fundar nuevas colonias civiles. Existió a lo largo del siglo un número indeterminado de familias y militares 
que se movían en función de las campañas contra los indios nómadas, y también de acuerdo a la oportunidad de formar parte de uno u otro proyecto de establecimiento. No es aventurado afirmar que los artículos de ambos reglamentos infundieron de un orden social específico a los individuos que formaban parte de estos movimientos y asientos. Otra manera de relacionar los proyectos de colonias militares con la colonización civil fue la referencia expresa que se hizo en 1848 sobre ello: entre las primeras disposiciones dictadas para apoyar a los colonos repatriados se indicaba que de preferencia éstos deberían arribar a las colonias militares (Camacho, 1991:85-89).

El caso específico de El Remolino permite hacer un seguimiento de la forma en que un proyecto de sociedad civil se desprendería paulatinamente del proyecto militar. El plano que se publicó en 1850, en donde se mostraban las áreas designadas para cuatro colonias militares a la orilla del Río Bravo (figura 2), define también el sitio específico para la colonia civil de El Remolino más hacia el sur. El problema consiste en saber en qué medida este último plan debía sujetarse a las reglas impuestas por el centro -la ciudad de México-, o bien, conocer si los argumentos para darle una independencia eran más fuertes dados los múltiples cambios e inestabilidad de los gobiernos estatales.

El año de 1850 se concedió a los colonos -dirigidos por Antonio Menchaca- el terreno necesario para formar una población civil en el punto que recibía el nombre de El Remolino. De acuerdo con lo dispuesto, Menchaca se comprometía a introducir en Coahuila un número de 100 familias mexicanas; si bien se le mencionaba como ciudadano, lo cierto es que también tenía el cargo de alférez. ${ }^{11}$ El plan no se consumó pero la medida había sido hecha, pues el expediente de recapitulación de los eventos, compilado por cierto en el tardío año de 1879 -pensando en poner orden a una situación que ya era caótica-, indicaba que el gobernador del Estado había designado los terrenos del punto de El Remolino como baldíos. ${ }^{12}$ Es pertinente la hipótesis de que la fundación de El Remolino constituía parte de algunos de los proyectos de cuatro colonias militares, aunque comenzada un tanto en posición exenta, a los sitios donde teóricamente se construirían los fuertes para cada nueva población.

11 Antecedentes relativos a la Congregación Remolino, Año de 1879, Archivo General del Estado de Coahuila (AGEC), FSxIx, C1, F8, E3, año de 1879.

12 Idem. 
La colonización se haría con familias que vivían en Nacogdoches, Texas, quienes desearían sujetarse a varias disposiciones del tratado de paz Guadalupe-Hidalgo para volver en calidad de repatriados al país y establecer una colonia. ${ }^{13}$ Debe contemplarse, sin embargo, que el primer plan de colonias militares fue "extinguido" por el año de 1853, y volvió a restablecerse el carácter móvil de las compañías presidiales (Rodríguez, 2001:VIII-IX). Pero al parecer el movimiento de colonización interna tenía ya una vida propia. En 1858, a pesar de que en apariencia el plan se encontraba en suspenso, se publicó una nota escrita por el gobernador de Nuevo León-Coahuila (Santiago Vidaurri) en donde se apoyaba a familias en Texas, concretamente de Béjar, para ir a colonizar el punto conocido como El Remolino. Las primeras ideas de estos segundos colonos habían sido formuladas por el comandante de escuadrón Manuel Leal, a quien ahora se le refería como civil y en adelante firmaría como "agente de la colonia". ${ }^{14}$

El mismo expediente también retoma otros problemas, como la definición de un proyecto más viejo y correspondiente a la nueva Villa de La Resurrección, que estaba destinada a fundarse en los terrenos del antiguo presidio de Agua Verde; y también la regularización de medidas para los "vecinos" que ya habitaban en la concesión antes dada a la colonia militar de Monclova Viejo (figura 2). Se giraron instrucciones al agrimensor Jesús Silva para que quedara a cargo del arreglo e hiciera la expedición de títulos de propiedad a partir de $1859.15 \mathrm{El}$ objetivo era definir, en un solo proyecto consolidado, lo que había resultado de una serie de iniciativas aisladas y que tendrían ahora como objetivo el sitio de El Remolino.

A través del expediente asoman muchos detalles interesantes, como el paulatino movimiento de los emigrados que vienen hacia el punto elegido en grupos de 30 y hasta 50 individuos; su asiento considerado como permanente mientras las autoridades resolvían las medidas definitivas que debían tomarse y, sobre todo, la constante referencia a los proyectos del coronel Castañeda, agente de la nueva Villa de La Resurrección, y del alférez Menchaca, agente de la del Remolino. Las medidas que se refieren a lo largo del

\footnotetext{
13 Idem.

14 Sobre el establecimiento de 200 familias emigradas de Béjar en el punto del Remolino en Coahuila, AGEC, FSxIx, C2, F5, E1, año de 1858.

15 Idem.
} 
mismo expediente hablan de la concesión de ocho sitios de ganado mayor con que inicialmente se había concebido el plan de cada colonia militar. Asimismo, se dieron disposiciones como que la nueva villa tuviera un aspecto regular y su "arreglo" -es decir, su trazo- respondiera a manzanas cuadradas con calles de 14 varas castellanas de anchura. Se refirió como prioridad que los primeros en llegar al sitio debían abocarse a la construcción de una acequia y a la edificación de casas en aras del ya repetido beneficio común. Se destinaron lotes urbanos a los colonos, agostaderos de disfrute común y terrenos de "propios" para provecho de toda la colonia. El punto de la distribución de tierras de labranza es interesante puesto que imponía tomar una decisión respecto a si dichas tierras habían de distribuirse en función de "los capitales" de los colonos, o bien, por "suertes" o partes iguales. ${ }^{16}$

Otro aspecto a recalcar es la confluencia de varios agrimensores en este proceso hasta cierto punto complicado. A Jesús Silva, último agrimensor nombrado, le correspondería poner en orden las labores de medida y organización practicadas por Francisco Oropeza (agrimensor de las colonias de oriente por nombramiento militar) y por Octaviano Blanco (agrimensor de la colonia de San Vicente y de la Villa de La Resurrección). La concesión final que se dio a El Remolino fue de cuatro sitios de ganado mayor. ${ }^{17}$ Pero en 1861 aparece un agrimensor más -Luciano de la Garza-, quien figura como representante del "vecindario del Remolino". En sus informes, De la Garza recuerda que existen problemas de jurisdicción en la posesión y acceso libre al agua del río, además de una solicitud previa para que la congregación sea erigida al nivel de villa. ${ }^{18}$ Había sido nombrado por una comisión encabezada por Severo Gómez, quien era vecino y daba cuenta de la necesidad de formalizar algunos trabajos; este último señalaba en su recuento: "nos hallamos en la Villa indicada más de sesenta individuos, los más con sus familias entregados todos a los trabajos preparatorios [...], y ya ha llegado el tiempo en que nos proponemos emprender nuestros trabajos de labranza, puesto que hemos concluido (aunque con mil afanes) la saca que debe regar muchas labores". 19

\footnotetext{
16 Idem.

17 Idem.

18 Idem.

19 Antecedentes relativos a la Congregación Remolino, Año de 1879, AGEC, FSxix, C1, F8, E3, año de 1879..
} 
Para 1863, Luciano de la Garza pudo dar una forma definitiva a la nueva población, pues hizo medidas de 124 solares y sus calles; señaló que como no había podido hacer las medidas respectivas a las caballerías de tierra, es decir, aquellas destinadas al cultivo, por el momento todos los habitantes estaban disfrutando el agua en común. ${ }^{20}$ La medida de la nueva población fue autorizada y firmada por Santiago Vidaurri en Monterrey, pues en este momento ambos estados de Nuevo León y Coahuila se mantenían unidos bajo un solo gobierno (un jefe militar). Se definiría una plaza de 100 varas en cuadro, a partir de la cual se trazarían las manzanas correspondientes y las calles de 16 varas castellanas de anchura. ${ }^{21}$

La relación entre los proyectos de colonias militares y civiles para el siglo XIX todavía aguarda un estudio completo. No conocemos, por ejemplo, el número de colonias para repatriados que se establecieron desde 1848, ni las formas de apoyo que ideó cada gobernador de los estados del norte. En todo caso, es interesante advertir a través de múltiples documentos oficiales cómo se tendía un velo sobre algo que parecía en realidad marchar de forma más bien autónoma. Manuel Siliceo, ministro de Fomento hacia 1857, por poner un ejemplo, cuando hizo su recuento sobre colonización señaló que no había tenido acceso a los expedientes de las colonias que se fundarían con repatriados, pues estos documentos -decía- habían sido enviados a las oficinas de guerra. Sin embargo, también afirmaba que las colonias militares ya no existían y que las colonias "de emigrados" no se habían formado (Memoria, 1857:44-45); como hemos visto, esta apreciación para nada era exacta.

Más adelante, la Estadística de Pérez, publicada en 1862, no dudaba en señalar la gran importancia y utilidad que podía llegar a tener este tipo de establecimientos, aunque también consideraba que todo "el sistema" estaba viciado desde sus bases (Pérez, 1862:279-284). En este contexto es interesante ver cómo se retomó la necesidad de contar con un plan general para toda la frontera durante el Segundo Imperio; y por lo mismo, continuaría hablándose de las "colonias agrícola-militares" (Memoria, 1866:518-519).

20 El comisionado de la medición del Remolino reclama el pago de sus honorarios, Villa de Rosas, Año de 1863, AgEc, Fsxix, C1, F2, E8, año de 1863.

21 Antecedentes relativos a la Congregación Remolino, Año de 1879, AGEC, FSxix, C1, F8, E3, año de 1879. 
En los informes oficiales del gobierno de Coahuila las cosas no eran muy diferentes, aunque abundaban en otro tipo de detalles. En general se expresaba una creciente expectativa de que "algún día" pudieran formarse dichas colonias militares. Pero la colonización interna avanza y, en El Remolino, se informa que desde 1868 ya se habían asentado indios lipanes, éxito considerado como rotundo bajo la idea de que su "reducción" era benéfica para la pacificación de todo el estado. Se estaba logrando uno de los principales incisos del anhelado plan -el de dulcificar las costumbres de "los bárbaros"-, pero ¿se estaba comprendiendo esto dentro de una perspectiva temporal amplia? (Memoria, 1869:10-15; Memoria, 1870:13-16; Memoria, 1886:23). Los informes de 1874 eran más precisos, pues al referirse a las colonias militares se recordaba que los diversos "movimientos revolucionarios" habían provocado que los regimientos y escuadrones destinados a establecerlas se disolvieran. Si bien bajo el nuevo plan de 1868 se había nombrado ya a un nuevo subinspector, ahora se enfrentaban nuevos problemas como la falta total de armamento y recursos para su establecimiento (Memoria, 1874:7).22

En las décadas de 1880 y 1890 parece que pocos serían los recuerdos de esta aventura y de sus raíces en los ambiciosos planes que suponían una cooperación específica entre gobiernos estatales y centrales, así como de la evidente proliferación de una idea de sociedad civil bajo los códigos de conducta dispuestos para la guerra contra el indio nómada -y su posible integración- en la frontera del noreste. El Anuario Coahuilense solamente indicaba que, dentro de la municipalidad de Zaragoza, existía un punto denominado "Congregación El Remolino", al igual que el Catecismo Geográfico publicado una década después (Portillo, 1886; Portillo, 1897).23

\footnotetext{
22 Memoria del Gobierno de Coahuila, Saltillo, Año de 1875, AGEc, FSxix, C19, F7, E4, año de 1875 .

23 Puede compararse esta revisión documental sobre El Remolino con la diferente valoración ofrecida por Romana Falcón (Falcón, 1991:363). Lo cierto es que, incluso durante los años de 1851 y 1852, se discutió el establecimiento de un destacamento de tropa en El Remolino. Véase Expediente relativo al establecimiento de un destacamento de tropa en el paraje llamado El Remolino, Agec, Fondo de Colonias Militares de Oriente (FCMO), C16, F6, E60, año de 1852.
} 


\section{La fragilidad de la memoria}

Un recorrido por la actual población de El Remolino -de cara a los ambiciosos planes que guiaron durante varias décadas su concreción- es sin duda muy desalentador. Pero resulta lo mismo para una enorme variedad de este tipo de pueblos que se ubican en el norte de Coahuila, relacionados con el movimiento de militares y colonos que -entre cambios de uno y otro régimen político- terminaban por abrazar la vida civil en condiciones muy precarias. En conjunto, ofrecen características similares: manzanas con muy pocas construcciones, lotes grandes y casi vacíos, muchas calles sin pavimento o banquetas, plazas rodeadas de espacios vacíos y un bajo número de habitantes -según datos del censo oficial- aunque en realidad muchos parezcan abandonados. Se trata de un interesante contexto para reflexionar acerca de los parámetros con que se valora la completitud y también sobre el sentido de la perfección misma. A todas luces parece evidente que los grandes proyectos pensados para ponerse en práctica y concluirse en un lapso corto sin duda adolecían de una falta de compaginación o correspondencia entre los fines y los medios que hace de todo planeador del espacio un organizador con capacidades y dotes de realismo. Al fallar dicha compaginación, el dibujo del plano urbano queda confinado al acervo de ciudades ideales: una ciudad que se alimentaba de la inspiración en el viejo régimen y se apuntaló en las condiciones reales y concretas de la presencia militar de borbones. No solamente es importante reconocer la militarización de esta región a lo largo del siglo xIx, sino también el despliegue -a partir de esta misma condición- de varias formas civiles de organización.

Durante el siglo xix la colonización civil adoptó muchas modalidades, en especial bajo el tipo de acuerdos que podían concertarse -o que era posible y oportuno formar- con los gobernadores de cada estado. La fragmentación de latifundios, como el de la familia Sánchez Navarro por 1867, también provocó nuevos movimientos de colonos que irían en busca de un sueño que quizás fue perdiendo sus detalles conforme avanzó el propósito de la fundación de una nueva población.

La persistencia de líneas rectas en damero -calles y manzanas en cuadro- probablemente comenzó en algún momento a aplicarse de forma automática por los agrimensores. Pero asombra que incluso al cobijo de estos planes, y ya en las postrimerías de 1890 -a decir del caso de la colonia civil de 
La Angostura, por ejemplo-, nunca pudieron llevarse a cabo los trazos de la nueva villa, pues el proyecto fue alcanzado por nuevas políticas que confiaban en los beneficios de los primeros repartos ejidales del siglo xx. En este sentido, el caso de los colonos de La Angostura es revelador porque además de justificar su derecho a recibir el ejido a inicios de la década de 1920 -por la modalidad de restitución, por asombroso que pueda parecer-, siempre insistieron en la continuada defensa de la frontera que hicieron frente a los ataques de "los salvajes" y el resguardo del territorio nacional desde largo tiempo atrás. ${ }^{24}$ Resulta sugerente que un gobernador coahuilense del siglo xx atribuyera precisamente a las colonias militares la persistencia de la propiedad comunal (Cepeda 2000:330).

Existen constantes que pueden señalarse en estos poblados que estuvieron llamados -en algún momento- a ser centro de grandes y populosas ciudades. La prospección de sitios es de mucha utilidad para el propósito, pues en sus características espaciales, constructivas y plásticas es posible discutir cuál sería la forma definitiva que se tenía pensada.

El patrón de asiento por lote responde, de modo poco variable, a la manzana dividida en cuatro partes iguales que varían entre 42 y 55 metros por lado. Generalmente se encontrarán pocos cuartos alineados hacia alguna de las calles, y en la parte posterior los grandes brocales de pozos o norias para extraer agua (fabricados con sillar de piedra o mampostería). También son frecuentes los trazos de acequia que surcan los poblados, y dado que cada lote es grande, hay posibilidad de cultivar una pequeña huerta. El cuarto pudo resolverse como una gran habitación "redonda", es decir, para usos múltiples (dormitorio, estancia, comedor), y oscila entre los seis metros de largo por cuatro de ancho, aunque también presenta variaciones y anexos que se van agregando.

Es posible que hacia finales del siglo xIX se subdividieran los lotes grandes y cuadrados, y con ello aparecieron otros cuartos que hicieron posible la formación de cintas completas de fachada continua de esquina a esquina de la manzana. Pero no en todos los pueblos pudo llegarse hasta este punto, sino al contrario, persistieron los espacios vacíos entre uno y otro cuarto. En general, sólo algunas manzanas muestran este tipo de asentamiento por lote -en las áreas centrales-, y las que se encuentran alrededor por lo gene-

24 Véase en Archivo del Comisariado Ejidal de Guadalupe Victoria (ACEGV), Coahuila. 
ral están completamente vacías. Algunos cuartos, sin embargo, revelan un grado de sofisticación en lo que toca a las técnicas de construcción empleadas. Un indicador del grado de refinamiento es la formación de un espacio de zaguán para dar paso hacia el recinto interior en donde incluso llega a anunciarse la formación de un patio. Éstas son algunas constantes de un gran número de pueblos del norte de Coahuila que surgieron entreverados con los proyectos para colonias militares y civiles; sobre sus vestigios se van acomodando modificaciones propias de nuestra época, e incluso se han derribado ya antiguas construcciones.

Figura 4

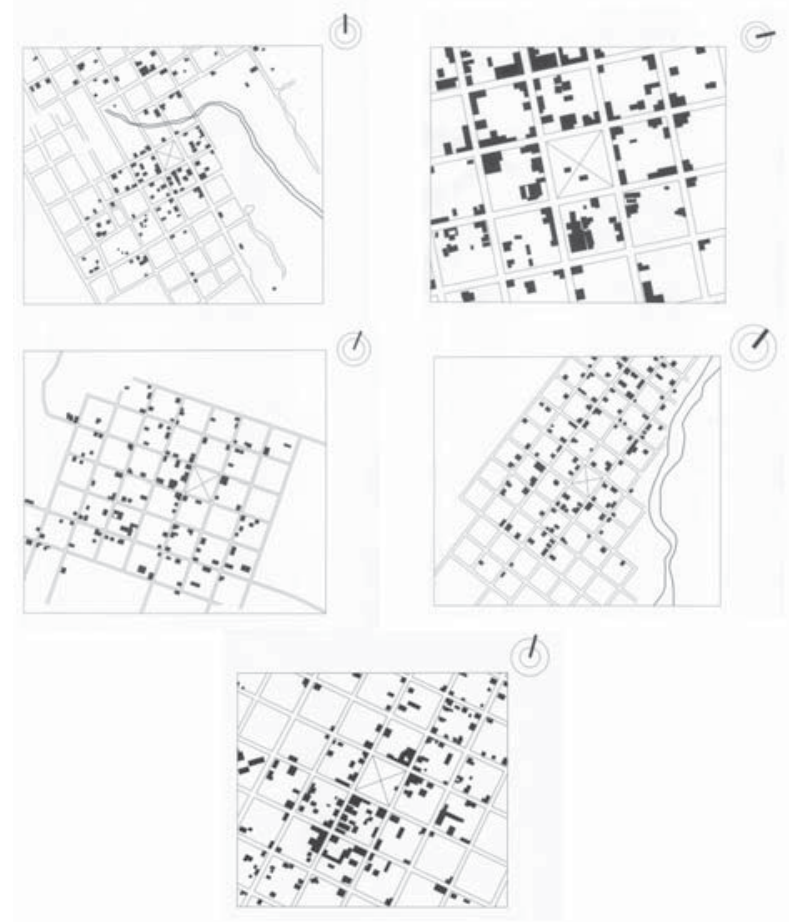

Patrón urbano de colonias civiles, en el norte de Coahuila: de izquierda a derecha, y de arriba hacia abajo, se trata de Hidalgo, Progreso, El Remolino, Juárez y San José del Aura. Obsérvese la dispersión de construcciones y la ausencia de manzanas consolidadas con edificaciones; además de abundar construcciones con materiales del lugar, tales como adobe y piedra. En últimos años se han practicado reformas nuevas en concreto, tabique y otros materiales contemporáneos. Dibujo calcado de fotografías aéreas del INEGI (2007). 


\section{Figura 5}

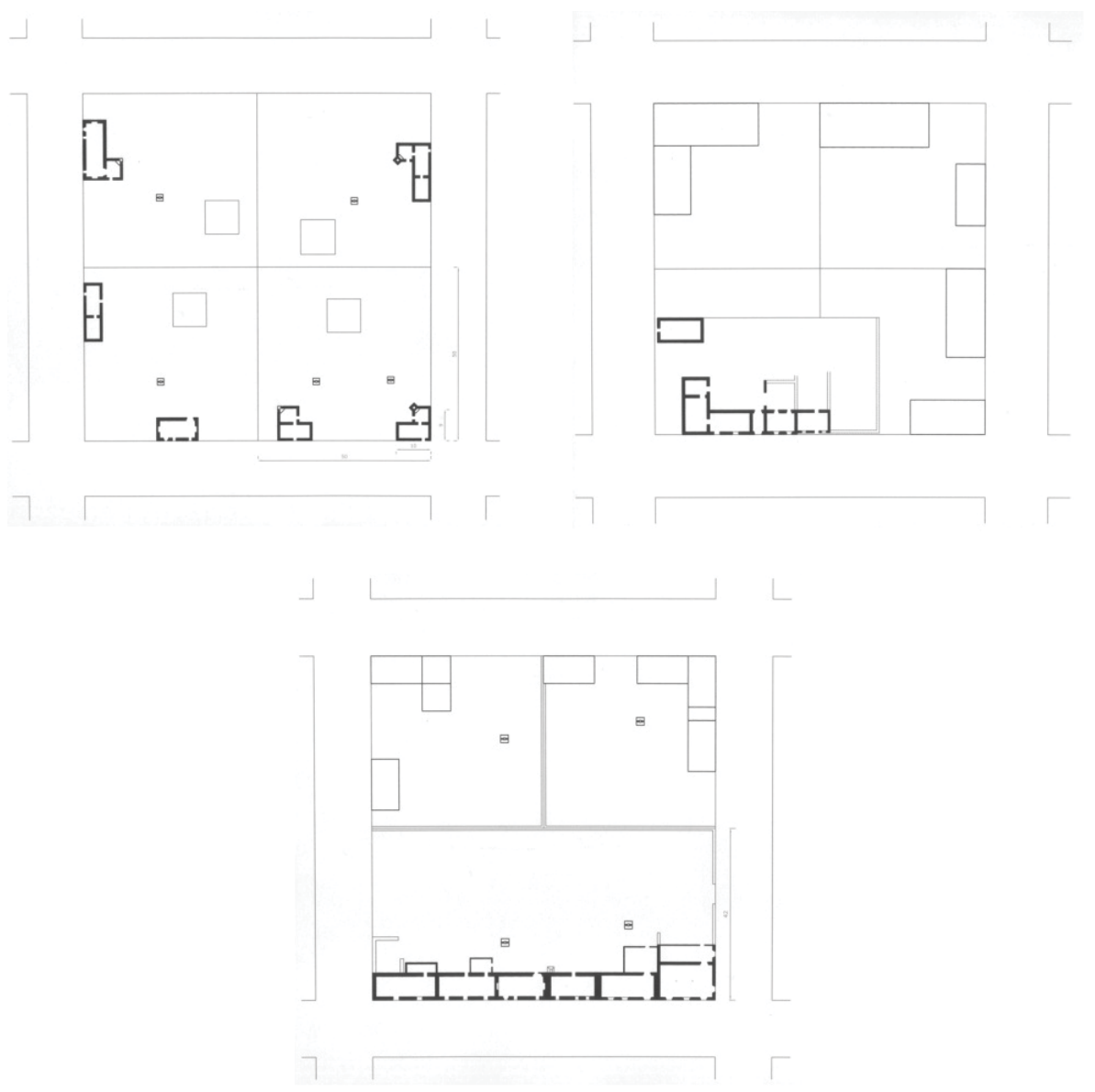

Ejemplos del patrón de asentamiento por lote y manzana, correspondientes a varias colonias civiles del norte de Coahuila. Hasta que las incursiones de indios continuaron siendo una constante, aproximadamente hasta la década de 1880, las construcciones mantuvieron características similares, como las pocas y pequeñas aberturas hacia el exterior en los muros (puertas y ventanas). El patrón superior, del lado izquierdo, define la distribución más básica de construcciones en el lote; le siguieron en grado de complejidad las dos variantes siguientes. Dibujo realizado por el autor mediante prospección física en El Remolino, El Progreso y San Juan de Sabinas, respectivamente (2007). 
Las construcciones por lo general se elevan sobre un cimiento de piedra. Están constituidas por tres tipos de muro mixto, aunque también abundan aquellos construidos únicamente con adobe. Los muros mixtos cuentan con una franja vertical de adobe, y sobrepuesta se encuentra una capa variable -aunque de bastante anchura, casi similar a la primera- de aparejo de piedra; dicho aparejo se presenta en tres modalidades: corte de cantería con una precisión digna de llamar la atención y rajuela en las juntas de unión, corte de piedra alternado con lajas que sirven de soporte e hincadas en el adobe, y-por último- mampostería irregular que protege la superficie de adobe. La variedad de estos aparejos permite suponer la importancia que tuvieron los ingenieros del cuerpo militar en la organización de la construcción en cada colonia, en especial para el primer caso. Por otra parte, los cuartos cuentan con muros anchos que varían entre 60 y 85 centímetros, es decir, tres cuartos y una vara castellana respectivamente. Asimismo, tienen pocas puertas y ventanas, aunque en las últimas décadas se hayan hecho nuevas aperturas por sentido de conveniencia de épocas más recientes. Esto es posible deducirlo ya que algunos vanos conservan dinteles construidos en adobe y piedra (señal del manejo de la estereotomía) con el acompañamiento de madera en el interior; por el contrario, en los más nuevos sólo se emplearon vigas de madera. Las techumbres están resueltas mediante morillos cortados con hacha y carrizo, tableta o tejamanil en el sentido transversal para contener el terrado -que está constituido de una mezcla de tierra, arena y cal-que fue humedeciéndose conforme pasó el tiempo hasta adquirir considerable dureza. Otras más recientes siguen el mismo esquema, aunque revelan modificaciones recientes por el uso de vigas demasiado estrechas más parecidas a un tablón. En algunas incluso se han introducido ya modificaciones como losas de concreto.

Los primeros colonos sólo pudieron construir algunos jacales con bajareque y con techumbres de material natural (hojas de palma de "soyate", por ejemplo). Los documentos en los archivos abundan en esta circunstancia, pues es preciso primero avanzar en las mediciones y sobre todo en la construcción de canales, y mientras tanto, resolver las necesidades de habitación con estructuras provisionales. Sin embargo, también las referencias a "jacales" y a "construcciones de terrado" es constante, que para ambos casos indican ya edificaciones permanentes. Los tipos de arquitectura que se muestran como constante en estos pueblos sin duda definen una etapa 
de consolidación hacia el último tercio del siglo XIX. Algunos vestigios de corte de piedra sugieren que, desde muy temprano, fue posible proceder con técnicas sofisticadas. Otras, por el contrario, son evidentes ejemplos de los inicios del siglo xx.

\section{Figura 6}
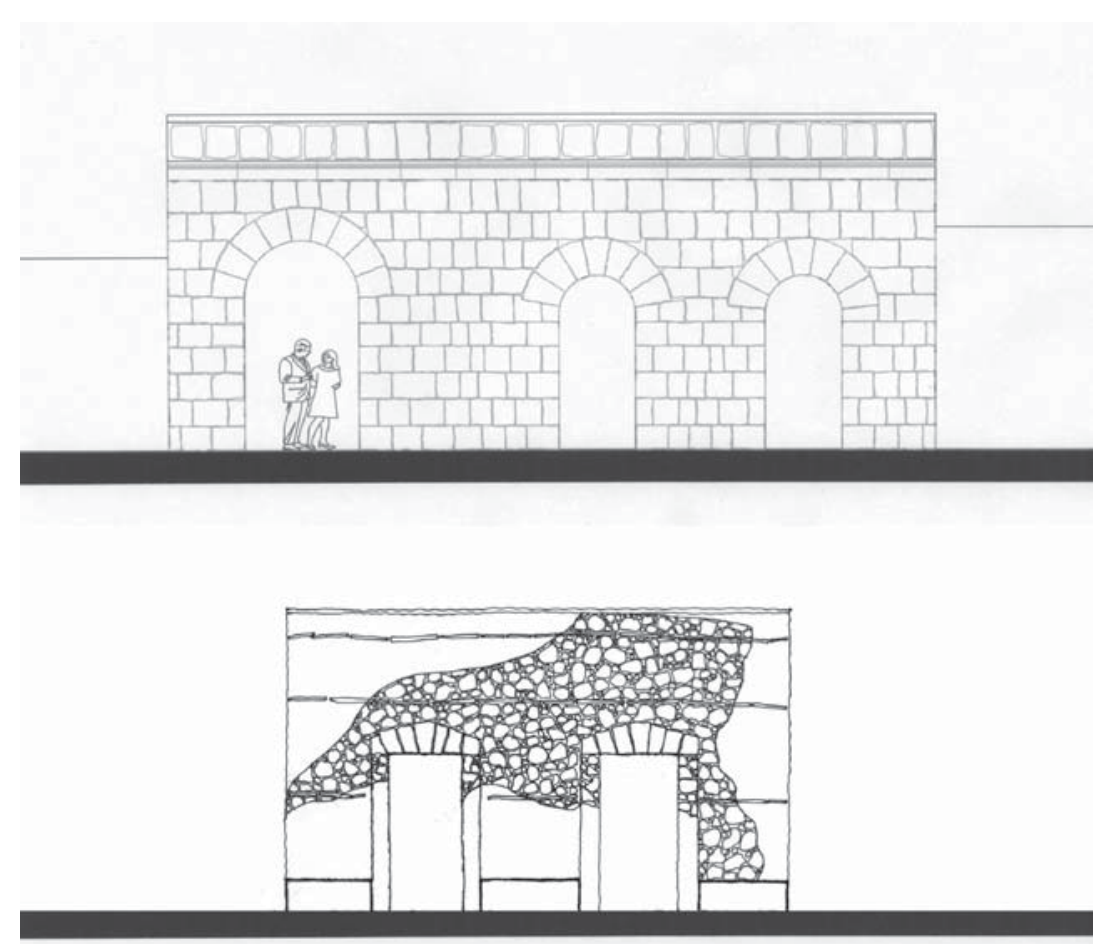

Ejemplos de fachada construida con claro dominio de la estereotomía en el corte de piedra. Es evidente el manejo de conocimientos propios de los grupos militares de ingenieros que se mantuvieron en campaña durante varias décadas. En los sitios pueden encontrarse varias combinaciones, generalmente acompañadas de un muro tejido (fabricado en adobe) con el de piedra. Es posible datar la construcción de esta casa sobresaliente (fig. superior) hacia la década de 1900 debido a las grandes aperturas de vanos más propias de una ciudad en donde ya no hay peligro por las incursiones de indios o bandidaje. El ejemplo inferior se remonta a varias décadas antes. Dibujo realizado por el autor, mediante prospección física en Villa del Progreso, Coahuila (2007). 
Ambos reglamentos para establecer colonias militares indicaron modelos a seguir para los trazados urbanos, no para ser aplicados de forma estricta sino como modelo de orientación. Pero el desenlace de los proyectos para cada colonia fue imprevisible, no sólo por el involucramiento de repatriados y civiles que dieron un nuevo aliento a cada una, sino también por sus cambiantes circunstancias de afianzamiento. A lo largo del siglo XIx, en el norte de Coahuila, la ciudad continuó imaginándose en sus formas y en su relación con las sociedades que anidaba. Es cierto que por encima de los modelos alternativos de las comunidades cooperativas de Owen, o prototipos de falansterios -ni qué decir sobre el paradigma de ciudades jardín y suburbios-, la experiencia del damero continuó ejerciendo una poderosa influencia para la posibilidad de fundar nuevas ciudades. Hoy nuestro conocimiento sobre estos proyectos y planes inconclusos es muy escaso, al grado de que nos hemos sido capaces de distinguir cuál fue el grado de completitud que llegaron a tener -que como bien mostré es algo mucho más que nada. La ciudad no se construye en un año o en una década; siempre ha sido una acumulación de formas de habitar. Pero la memoria es frágil, aunque hable la lengua de la fortificación.

\section{Bibliografía}

Avilés Fernández, Miguel (1976), Sinapia, una utopía española del Siglo de las Luces, Madrid, Editora Nacional.

Berninger, Dieter G. (1974), La inmigración en México, 1821-1857, México, Secretaría de Educación Pública.

Camacho, Hortencia (1991), Fundaciones y asentamientos en Nuevo León, siglos XVIII y XIX, Zuazua, Universidad Autónoma de Nuevo León.

Cepeda, Francisco (2000), "Un siglo de modernización”, en Breve historia de Coahuila, México, Fondo de Cultura Económica.

Colonias Militares, Plan para su establecimiento en las fronteras de oriente y occidente de la República (1848), México, Imprenta de I. Cumplido.

De la Peña, M. (1950), "Problemas demográficos y agrarios", Problemas agrícolas $e$ industriales de México, 3 y 4/ II, jul-sept/oct-dic, pp. 9-324.

Diario de viaje de la Comisión de Limites que puso el Gobierno de la República, bajo la dirección del Exmo. Sr. General de división D. Manuel de Mier y Terán (1850), México, Tipografía de Juan R. Navarro.

Diccionario de la legislación mexicana, que comprende las leyes, decretos, bandos, reglamentos, circulares y providencias del Supremo Gobierno y otras autoridades de la nación, publica- 
dos desde el 31 de mayo de 1863 hasta el 30 de septiembre de 1868, formado por Luis G. Zaldivar (1868), México, Imprenta de la Constitución Social.

Exposición del sistema métrico decimal y Tabla de equivalencias (1895), México, Oficina Tipográfica de la Secretaría de Fomento.

Falcón, Romana (1991), "Poderes y razones de las Jefaturas Políticas, Coahuila en el primer siglo de vida independiente”, en Alicia Hernández Chávez y Manuel Miño Grijalva (coord.), Cincuenta años de historia en México, vol. 2, Cincuentenario del Centro de Estudios Históricos, México, El Colegio de México.

García Cantú, Gastón (1963), Utopias mexicanas, México, Era.

González de la Vara, Martín (2000), "The return to Mexico, the relocation of new mexican families to Chihuahua and the conformation of a frontier region 18481854", en Erlinda Gonzales-Berry y David R. Maciel (eds.), The contested homeland. A chicano history of New Mexico, Alburquerque, University of New Mexico Press.

González Navarro, Moisés (1960), La colonización en México, 1877-1910, México, Taller de Estampillas y Valores.

Gutiérrez, Laura (2000), "El prolongado ocaso de un estado y la gestación de otro", en Breve historia de Coahuila, México, Fondo de Cultura Económica.

Jiménez, Alfredo (2006), El gran norte, una frontera imperial en la Nueva España (15401820), Madrid, Tébar.

Junta de Colonización (1865), en Diario del Imperio II/192.

Memoria del Ministro de Guerra y Marina presentada a las Cámaras del Congreso General Mexicano, en enero de 1840 (1840), México, Oficina del Águila.

Memoria del Secretario de Estado y del Despacho de Guerra y Marina leída en la Cámara de Senadores el día 10 y en la de Diputados el día 11 de marzo de 1845 (1845), México, Imprenta de Vicente García Torres.

Memoria del Ministerio de Estado y del Despacho de Guerra y Marina del Gobierno Supremo de la República Mexicana, leída al augusto Congreso Nacional el día 9 de diciembre de 1846 por el General Almonte (1846), México, Imprenta de Torres.

Memoria del Secretario de Estado y del Despacho de Guerra y Marina, leída en la Cámara de Diputados el día 9, y en la de Senadores el 11 de enero de 1849 (1849), México, Imprenta de Vicente García Torres.

Memoria del Secretario de Estado y del Despacho de Guerra y Marina, leída en la Cámara de Diputados el 3, y en la de Senadores el 4 de enero de 1851 (1851), México, Imprenta de V. Torres.

Memoria que el Vice-gobernador del Estado, en ejercicio del Supremo Poder Ejecutivo, presentó al Honorable Congreso el día 2 de enero de 1851 (1851), Saltillo, Imprenta del Supremo Gobierno, dirigida por Macedonio García y Ramos.

Memoria del Secretario de Estado y del Despacho de Guerra y Marina, leída en la Cámara de Diputados los días 30 y 31 de enero, y en la de Senadores en 13 de febrero de 1852 (1852), México, Imprenta de Vicente G. Torres. 
Memoria de la Secretaría de Estado y del Despacho de Fomento, Colonización, Industria y Comercio de la República Mexicana, escrita por el Ministro del ramo C. Manuel Siliceo para dar cuenta con ella al soberano Congreso Constitucionalista (1857), México, Imprenta de Vicente García y Torres.

Memoria presentada a S. M. El Emperador, por el ministro de Fomento Luis Robles Pezuela de los trabajos ejecutados en su ramo el año de 1865 (1866), México, Imprenta de José María Andrade y F. Escalante.

Memoria que el gobernador del estado de Coahuila de Zaragoza presentó al Congreso el 2 de enero de 1869 (1869), Saltillo, Imprenta del Gobierno a cargo de M. M. Pepi.

Memoria que presentó al Congreso el C. Gobernador de Coahuila de Zaragoza, el 21 de noviembre de 1870 (1870), Saltillo, Tipografía del Gobierno a cargo de F. F. Ozuna.

Memoria con que el Gobierno Provisional de Coahuila da cuenta al 3er Congreso Constitucional del mismo, del estado en que se hallan los ramos de la administración pública (1874), Saltillo, Tipografía del Gobierno a cargo de Florencio Fernández Ozuna.

Memoria que el General Julio M. Cervantes, Gobernador del Estado de Coahuila presenta a los habitantes del mismo de los diferentes ramos de la administración pública (1886), Saltillo, Tipografía del Gobierno en Palacio, dirigida por Juan Molina.

Oliveras Samitier, Jordi (1998), Nuevas poblaciones en la España de la Ilustración, Barcelona, Fundación Caja de Arquitectos.

Pérez Hernández, José María (1862), Estadística de la República Mexicana, Guadalajara, Tipografía del Gobierno.

Ponce de León, José María (1910), Reseñas históricas del estado de Chihuahua, tomo I, Chihuahua, Imprenta del Gobierno, dirigida por G.A. de la Garza.

Portillo, Esteban L. (1886), Anuario Coahuilense para 1886, Saltillo, Tipografía del Gobierno en Palacio, dirigida por Juan Molina.

Portillo, Esteban L. (1897), Catecismo geográfico, político e histórico del estado de Coahuila de Zaragoza, Saltillo, Tipografía del Gobierno en Palacio, dirigida por Severiano Mora.

Reglamento para el establecimiento de las colonias militares en la frontera del norte (1869), México, Imprenta del Gobierno en Palacio, a cargo de José M. Sandoval.

Rodríguez, Francisco Javier (2001), "El proyecto de las colonias militares de la frontera de oriente, 1848-1853”, en Colonias Militares de Oriente, Catálogo del Fondo Documental, Ramos Arizpe, Instituto Estatal de Documentación, Información y Estadística.

Rosenau, Helen (1999), La ciudad ideal, Madrid, Alianza.

Velázquez, María del Carmen (1979), Tres estudios sobre las Provincias Internas de Nueva España, México, El Colegio de México.

Vercelloni, Virgilio (1996), La cité idéale en Occident, París, Éditions du Felin. 


\section{Archivos citados}

Archivo Histórico del Congreso del Estado de Nuevo León (AHCENL)

Archivo General del Estado de Coahuila (AGEC)

Archivo del Comisariado Ejidal de Guadalupe Victoria (ACEGV)

Mapoteca Manuel Orozco y Berra (ммоув)

Artículo recibido el 7 de junio de 2011

Segunda versión recibida el 8 de diciembre de 2011

Artículo aprobado el 12 de enero de 2012 